\title{
Estado punitivo e pós-modernidade
}

\author{
Debora Regina Pastana \\ Doutora em sociologia (Universidade Estadual de São Paulo) \\ Professora da Universidade Federal de Uberlândia \\ deborarepastana@bol.com.br
}

\begin{abstract}
Resumo O tema central deste artigo é o investimento crescente no combate ao crime pelas democracias contemporâneas, o que contribui para consolidar, também no Brasil, a figura do "Estado punitivo". Inserido nas recentes reflexões sociológicas de Loïc Wacquant, David Garland, Nils Christie e Zygmunt Bauman, entre outros, esse tema é ainda pouco discutido pela comunidade acadêmica nacional. $\mathrm{O}$ atual arranjo capitalista generaliza-se quase que instantaneamente em todo o globo, atrelando o sucesso dos empreendimentos econômicos à nova face da política criminal. $\mathrm{O}$ artigo, portanto, tem como objetivo oferecer um enfoque alternativo às reflexões sobre o controle social, abordando o que se convencionou chamar de "Estado punitivo", figura política que se ajusta às transformações econômicas, sociais e culturais já em curso nos últimos trinta anos e que, segundo alguns teóricos contemporâneos, inauguram a pós-modernidade.
\end{abstract}

Palavras-chave: Estado punitivo, democracia, pós-modernidade.

\begin{abstract}
Nos dois lados do Atlântico, sentenças condenatórias, direitos das vítimas, leis de vigilância comunitária, policiamento privado, políticas de "lei e ordem" e uma enfática crença de que a prisão funciona se tornaram lugarescomuns no cenário do controle do crime [..]. Mas o aspecto mais estarrecedor destas políticas criminais é que qualquer uma delas surpreenderia (ou talvez até mesmo chocaria) um historiador que, há alguns anos, observasse este cenário. (Garland, 2008, p. 41)
\end{abstract}

A o iniciar qualquer estudo científico acerca dos sistemas punitivos atuais é necessário, precipuamente, contextualizá-los politicamente. Este artigo pretende focalizar a observação do sistema punitivo contemporâneo sob esse viés e, para tanto, propõe uma análise concatenada com o atual panorama político.

Destaca-se no contexto político atual uma forte preocupação com a gestão da segurança pública. É cada vez mais evidente a atenção estatal com o controle penal. O intuito deste artigo, portanto, é analisar criticamente a ampliação do combate ao crime no mundo contemporâneo. Tal ampliação é cada vez mais emblemática nas sociedades democráticas contemporâneas, refletindo um novo paradigma de controle social traduzido não apenas em um exercício autoritário, mas, acima de tudo, numa atuação antidemocrática hegemonicamente reconhecida como necessária.

Essa marca ostensiva relacionada à segurança pública une todos os setores do Estado em um único discurso e em uma ação coordenada que, de forma implacável, fragiliza significativamente o ambiente democrático. Nesse contexto, a gestão da segurança pública é "concebida e executada não tanto por ela mesma, mas sim com a finalidade expressa de ser exibida e vista, examinada e espionada: a prioridade absoluta é 
fazer dela um espetáculo, no sentido próprio do termo" (Wacquant, 2007, p. 9).

Tal postura política parte de um modelo liberal estabelecido no final dos anos 1970 e se sobrepõe aos regimes democráticos, ainda que formalmente não contraste com os textos constitucionais. Por certo que os Estados nacionais vêm sofrendo um processo de reconfiguração política adequada ao receituário neoliberal. Liberação dos mercados, privatização das indústrias e serviços, desregulamentação das relações de trabalho, flexibilização salarial e redução das políticas públicas de inclusão social são características desse novo modelo de gestão pública evidenciadas desde o tão aclamado "Consenso de Washington".

Tais mudanças apontam para um momento histórico que Anthony Giddens (1995) chama de "modernidade tardia", Ulrich Beck (1995) de "modernidade reflexiva", Zigmunt Bauman (2001) de "modernidade líquida" e alguns outros teóricos ${ }^{1}$ contemporâneos de "pós-modernidade". O tempo em que vivemos agora é, em grande parte do mundo, marcado pela diminuição de políticas sociais e pelo aumento de políticas penais.

Compreender essa nova configuração política, mais combativa diante dos conflitos sociais, e pouco preocupada em questionar a origem deles, é de fundamental importância para as Ciências Sociais, na medida em que permite desvendar as atuais tendências autoritárias hegemonicamente articuladas em praticamente todo o globo.

Se é certo que "a emergência da pós-modernidade está estritamente relacionada à emergência desta nova fase do capitalismo avançado, multinacional e de consumo" (Jameson, 1985, p. 10), em matéria penal ela se evidencia por meio do endurecimento generalizado das políticas penais, judiciárias e penitenciárias.

Recentemente parte considerável da humanidade se vê inserida na tendência homogênea de obsessão securitária. De acordo com Loïc Wacquant, "a inconteste hegemonia do pensamento neoliberal sobre segurança dos dois lados do Atlântico" associou a "mão invisível' do mercado do trabalho desqualificado com o seu prolongamento ideológico e seu complemento institucional no 'punho de ferro' do Estado penal" (Wacquant, 2007, p. 40).

Ainda segundo Wacquant (2001, p. 7), a "penalidade neoliberal apresenta o seguinte paradoxo: pretende remediar com um 'mais Estado' policial e penitenciário o 'menos Estado' econômico e social que é a própria causa da escalada generalizada da insegurança objetiva e subjetiva em todos os países".

De fato, "a atrofia planejada do Estado Social [...] e a súbita hipertrofia do Estado Penal são dois movimentos concomitantes e complementares" (Wa- cquant, 2007, p. 40). O advento de uma economia marcada pelo abandono do compromisso keynesiano e pela acumulação flexível produziu o agravamento das desigualdades sociais e dos processos de exclusão social em escala global. Em contrapartida, os governos locais se apresentam como os principais responsáveis pelo controle das consequências desses processos.

No mundo das finanças globais, os governos detêm pouco mais que o papel de distritos policiais superdimensionados; a quantidade e qualidade dos policiais em serviço, varrendo os mendigos, perturbadores e ladrões das ruas, e a firmeza dos muros das prisões assomam entre os principais fatores de "confiança dos investidores" e, portanto, entre os dados principais considerados quando são tomadas decisões de investir ou de retirar um investimento. Fazer o melhor policial possível é a melhor coisa (talvez a única) que o Estado possa fazer para atrair o capital nômade a investir no bem-estar dos seus súditos; e assim o caminho mais curto para a prosperidade econômica da nação e, supõe-se, para a sensação de "bem-estar" dos eleitores, é a da pública exibição de competência policial e destreza do Estado. (Bauman, 1999, p. 128)

O controle do crime nas democracias liberais do Ocidente realmente pretende-se absoluto. Para tanto, os Estados organizam, de maneira autoritária e simbólica, suas políticas penais, implementadas para reforçar a função essencial do Estado burguês: "a garantia do sono tranquilo do proprietário de Adam Smith e a redução do risco da morte violenta que atemorizava Thomas Hobbes" (Paixão e Beato, 1997, p. 2).

Se as mesmas pessoas que exigem um Estado mínimo, a fim de "liberar" as "forças vivas" do mercado e de submeter os mais despossuídos ao estímulo da competição, não hesitam em erigir um Estado máximo para assegurar a "segurança" no quotidiano, é porque a pobreza do Estado social sobre o fundo da desregulamentação suscita e necessita da grandeza do Estado penal. É porque esse elo causal e funcional entre os dois setores do campo burocrático é tanto mais forte quanto mais completamente o Estado se livra de qualquer responsabilidade econômica e tolera, ao mesmo tempo, um elevado nível de pobreza e uma pronunciada ampliação da escala das desigualdades. (Wacquant, 2007, p. 48)

Contudo, é importante destacar que tal realidade é específica do momento que vivenciamos. Como Garland (2008) faz questão de frisar, é a "história do presente". Nas décadas anteriores a 1970, as taxas de criminalidade mantinham-se estáveis nos países de- 
senvolvidos e o controle do crime era fundamentado em um pensamento criminológico que sustentava a necessidade de tratamento correcional individualizado ao delinquente. A solução para o crime residia na reabilitação dos criminosos, no amparo aos familiares e na adoção de medidas de inclusão social. O controle moderno era pautado pela restrição do poder estatal, pela ampliação das penas alternativas à prisão e pelo abandono sistemático do encarceramento considerado ultima ratio do sistema penal.

No sistema de bem-estar do pós-guerra, a prisão era vista como uma instituição problemática, necessária como último recurso, porém contraproducente e desorientada com relação aos objetivos correcionais. Despendeu-se muito esforço governamental na tarefa de se criar alternativas ao encarceramento e no estímulo a que as sentenças as aplicassem. Na maior parte do século XX, aparentemente existiu um movimento secular de distanciamento da prisão no sentido de aplicação de penas pecuniárias, do livramento condicional e de muitas outras formas de supervisão comunitária. (Garland, 2008, p. 59)

Retratando o controle social desse período, $\mathrm{Mi}$ chel Foucault (1987) argumenta que a abordagem criminológica traduzia a lógica da moderna sociedade ocidental. A metáfora do panóptico de Bentham foi interpretada por Foucault como símbolo dos desejos modernos de disciplina e assimilação. O Direito Penal, nesse contexto, pretendia readaptar delinquentes adequando o comportamento desviante aos valores triunfantes da sociedade moderna, vale dizer, ordem, trabalho e progresso urbano-industrial.

A hipótese foucaultiana para a prisão era a de que ela esteve "desde sua origem, ligada a um projeto de transformação dos indivíduos. [...] Desde o começo a prisão devia ser um instrumento tão aperfeiçoado quanto a escola, a caserna ou o hospital" (Foucault, 1995, p. 131).

Enquanto perduraram justificativas iluministas de cunho contratual ${ }^{2}$ para o sistema punitivo, suas finalidades foram sempre associadas à disciplina utilitarista. A punição nada mais era que o exercício continuado e ininterrupto do treinamento correcional.

A ideologia da pena era a do treinamento, mediante controle estrito da conduta do apenado, sem que este pudesse dispor de um só instante de privacidade. Essa ideologia será expandida e formulada pelos diversos criadores de regimes e sistemas "progressivos", mas no fundo seguirá sendo a mesma: vigilância, arrependimento, aprendizagem, "moralização" (trabalhar para a felicidade). Em geral, corresponde à forma de trabalho industrial, tal como era concebida e praticada na época: a vigilância estrita do trabalhador na fábrica, o controle permanente pelo capataz, a impossibilidade de dispor de tempo livre durante o trabalho etc. (Zaffaroni, 2002, p. 279)

Enfim, o controle social foi concebido, nesse momento, como treinamento para os desordeiros da modernidade. Conter as massas carentes e, ao mesmo tempo, discipliná-las para o trabalho fabril era o objetivo central da maioria dos projetos de desenvolvimento da sociedade capitalista.

Tal estratégia antropofágica, como sugeriu LéviStrauss (1996), baseia-se no permanente enfrentamento da alteridade a partir da domesticação e da consequente homogeneização do comportamento desviante.

Nesse contexto o delinquente é visto como um desajustado carente de reabilitação. Princípios penais-previdenciários atribuíam à punição um caráter reformador. A reabilitação buscava aliar controle com cuidado, punição com correção, ordem com bem-estar.

Contudo, a partir de 1970, o discurso criminológico muda radicalmente, passando a identificar o delinquente como "indivíduos fortemente propensos a assumir condutas egoístas, antissociais e criminosas a menos que sejam inibidos de fazê-lo por controles robustos e eficazes" (Garland, 2008, p. 61).

Cada vez mais a criminologia contemporânea sustenta a ineficácia da reabilitação penal, abrindo caminho para a legitimação da punição meramente retributiva. Esse novo paradigma altera a imagem das classes populares carentes de políticas sociais e os configura como inaptos, quando não simples parasitas do Estado (Salla; Gauto; Alvarez, 2006, p. 334).

Verifica-se também o abandono do discurso criminológico ressocializador ${ }^{3}$ permitindo, cada vez mais, a consideração da punição como simples "instrumento de encerramento de uma população considerada tanto desviante e perigosa como supérflua, no plano econômico". Tal punição representa tão somente um mecanismo útil para "segregar uma ca-

2. Ao explicar tais justificativas, Zaffaroni (2002) argumenta que a sociedade moderna, ao se estabelecer mediante um contrato, determina que o homem que pretende alcançar a riqueza por uma via não autorizada por aquele viola o que o contrato preceitua. "Qual é a sanção para quem viola o contrato? Uma reparação, uma indenização. Quando um cidadão não paga uma indenização devida como resultado da violação de um contrato, é forçado a fazê-lo (dele é expropriado algo de valor), mas os homens da massa criminalizada por esse controle social nada possuíam. O que deles se expropriava? A única coisa que podiam oferecer no mercado: sua capacidade de trabalho, sua liberdade. Daí a ideologia que faz da privação da liberdade uma pena, que até então havia sido apenas uma medida preventiva (o que hoje chamamos 'prisão preventiva') durante o processo, pois as penas eram corporais" (Zaffaroni, 2002, p. 263).

3. Figura criada no contexto iluminista para ilustrar a regeneração do infrator amansado pelo sistema jurídico-burguês. 
tegoria indesejável, percebida como provocadora de uma dupla ameaça, inseparavelmente física e moral" (Wacquant, 2001, p. 98).

Uma das características dos novos sistemas penais do empreendimento neoliberal consiste numa radical transformação nas finalidades da privação de liberdade, que passam daquilo que Zaffaroni chamou de 'ideologias re’ (reinserção social, recuperação laborativa, redisciplinamento etc.) a uma assumida técnica de neutralização do condenado. (Batista, 2000, p. 107) (sic)

De fato, como assevera Guindani (2005, p. 8), "o conceito de reabilitação foi totalmente desmistificado a partir dos anos 80 e as teorias que assumiam a punição como forma de tratamento e ressocialização foram desmascaradas [...] diante de argumentos ambíguos sobre a execução penal”. O que deveria ser um dos pilares para a construção de um Estado Democrático de Direito passou a ser ilegítimo e irracional.

Por certo, não há como sustentar a ideia de ressocialização da punição em um ambiente onde as instituições de ordem (polícia, tribunais e prisões) adquirem legitimidade somente quando atuam de forma violenta e destrutiva. Uma sociedade cada vez mais determinada pelo individualismo e pela exclusão social sequer vê sentido em associar punição com recuperação. Cada vez mais impregnada pelos valores liberais, presentes no mundo atual, que naturalizam a exclusão à semelhança do darwinismo social, essa sociedade condena sumariamente o infrator, desejando imediatamente seu descarte.

Enfim, essa nova configuração penal evidencia o investimento cada vez maior dos Estados em ações repressivas e severas e explicita nítidos contornos de um "Estado punitivo" que se ajustam ao atual panorama econômico e social externado pelo recente modelo capitalista de desenvolvimento. É justamente essa associação que vai determinar um novo enfoque nas reflexões sobre o controle social em nível global e nacional. É, portanto, essencial poder identificar posturas ordinariamente punitivas que caracterizam o Estado punitivo e a consequente criminalização da miséria.

Assim, é fundamental compreender a condições históricas das quais dependem as práticas contemporâneas de controle social. Essa "preocupação crítica em entender o presente" (Garland, 2008, p. 42) aponta para um novo contexto, para uma nova ordem.

Partindo dessa premissa, busca-se "identificar os interesses políticos e os significados culturais que amparam essas novas práticas, assim como os mecanismos específicos que ligam as instituições do controle do crime a outros domínios sociais" (Garland, 2008, p. 43).

Os recentes desdobramentos em matéria de controle do crime e da justiça criminal são intrigantes por- que envolvem uma súbita e perturbadora subversão do padrão histórico assentado. Mostram uma aguda descontinuidade que reclama explicação. Os processos modernizantes que, há tão pouco tempo, pareciam sedimentados neste domínio - acima de todas as tendências de longo prazo que apontavam para a "racionalização" e para a civilização" - agora aparentam ter engatado a marcha à ré. A reaparição, na política oficial, de sentimentos punitivos e de gestos expressivos, que parecem estranhamente arcaicos e absolutamente antimodemos, tende a confundir as teorias sociais comuns sobre a punição e seu desenvolvimento histórico. Nem mesmo o mais criativo leitor de Foucault, Marx, Durkheim e Elias poderia prever estes desdobramentos recentes, e certamente nenhuma previsão deste tipo jamais surgiu. (Garland, 2008, p. 44)

Ao contrário da política penal-previdenciária, cuja concepção básica era a reforma e a intervenção social para prevenir e combater o crime, a atual forma de conceber as políticas de combate à criminalidade abandona a perspectiva humanista de reinserção do criminoso para focalizar a simples imposição de mecanismos de controle.

Durante uma boa parte do século XX, a expressão abertamente confessada do sentimento de vingança foi virtualmente tabu, pelo menos da parte dos representantes do Estado, mas, nesses últimos anos, tentativas explícitas de expressar a cólera e o ressentimento do público tornaram-se um tema recorrente da retórica que acompanha a legislação penal e a tomada de decisões. Os sentimentos da vítima, ou da família da vítima, ou um público temeroso, ultrajado, são agora constantemente invocados em apoio a novas leis e políticas penais. O castigo - no sentido de uma sanção significativa que apela para o sentimento do público - é uma vez mais um objetivo penal respeitável, abertamente reivindicado. (Garland, 1999, p. 61)

Na pós-modernidade, emerge um novo cenário no que diz respeito à criminalidade e a seu controle na sociedade contemporânea. Em decorrência da maior degradação social, deflagrada pelas mudanças econômicas e políticas, ressurge com força máxima desejos explicitamente retributivos e leis draconianas traduzidas em políticas penais unicamente punitivas.

E o que torna uma política criminal unicamente "punitiva"? Na busca por esclarecimento, e utilizando a perspectiva de Garland (1999), o que é que poderia justificar a descrição de uma trajetória de um Estado como "punitivo"?

A resposta é mais complexa do que parece. A "punitividade”, de fato, em parte é um juízo compara- 
tivo acerca da "severidade" das penas com relação às medidas penais precedentes, em parte depende dos objetivos e das justificativas das medidas penais, assim como também da maneira pela qual a medida é apresentada ao público. As novas medidas que aumentam o nível das penas, reduzem os tratamentos penitenciários, ou impõem condições mais restritivas aos delinquentes colocados em liberdade condicional ou vigiada [...] podem ser consideradas "punitivas", pois aumentam com relação a um ponto de referência anterior. (Garland, 1999, p. 60)

Assim, a maior parte das medidas penais recentes, engajadas em um modo de ação que expressa a necessidade constante de punição severa, traduzindo o sentimento público de intranquilidade e insegurança e insistindo nos objetivos retributivos ou denunciadores, atesta, ao mesmo tempo, seu caráter inequivocamente "punitivo". Esse modelo político é ainda mais sedutor e mais funesto quando aplicado em países com fortes desigualdades sociais e desprovidos de tradição democrática como é o caso brasileiro.

Se, no sistema de bem-estar do pós-guerra, a prisão era vista como uma instituição falida, destinada aos presos perigosos e como último recurso de controle social, agora a opinião dominante é que "a prisão funciona”.

Em nítido contraste com a sabedoria convencional do período passado, a opinião dominante agora é a de que "a prisão funciona" - não como um mecanismo de reforma ou de reabilitação, mas como instrumento de neutralização e de retribuição que satisfaz as exigências políticas populares por segurança pública e punições duras. Os anos recentes testemunharam uma notável reviravolta nos destinos da prisão. Esta instituição, com longa história de expectativas utópicas e de tentativas periódicas de reinvenção - primeiro como penitenciária, depois reformatório e, mais recentemente, como estabelecimento correcional -, finalmente viu suas ambições reduzidas ao terreno da neutralização e da punição retributiva. No curso, porém, desta mudança de status, a prisão novamente se transformou. Ao longo de poucas décadas, ela deixou de ser uma instituição desacreditada e decadente para se tornar um maciço e aparentemente indispensável pilar da ordem social contemporânea. (Garland, 2088, p. 59-60)
A consequência imediata, percebida em várias democracias contemporâneas, é o aumento significativo e preocupante do número de detentos. Em tempos pós-modernos, a população carcerária aumenta em escala assustadora, produzindo uma ordem social marcadamente aniquiladora.

Segundo pesquisa do International Centre for Prisions Studies, do King's College London (Walmsley, 2009), existia no mundo, em dezembro de 2008, cerca de 9,8 milhões de pessoas presas. De fato, as populações prisionais crescem em muitas partes do globo. De acordo com a Lista Mundial da População Prisional (Walmsley, 2009), a população carcerária aumentou em 71\% nos países pesquisados (em 64\% dos países da África, 83\% dos países das Américas, 76\% dos países da Ásia, 68\% dos países da Europa e $60 \%$ dos países da Oceania).

\begin{tabular}{|l|c|c|}
\hline \multicolumn{3}{|c|}{$\begin{array}{c}\text { População carcerária mundial } \\
\text { (alguns países) - 2008 }\end{array}$} \\
\hline País & Total de presos & Por 100 mil hab. \\
\hline EUA & 2.293 .157 & 756 \\
\hline Rússia & 891.738 & 629 \\
\hline China & $1.565,771$ & 119 \\
\hline Brasil & 440.013 & 237 \\
\hline Índia & 373.271 & 33 \\
\hline México & 222.671 & 207 \\
\hline Japão & 81.255 & 63 \\
\hline Inglaterra & 83.392 & 153 \\
\hline Espanha & 73.687 & 160 \\
\hline Alemanha & 73.203 & 89 \\
\hline Colômbia & 69.689 & 149 \\
\hline Argentina & 60.621 & 154 \\
\hline Chile & 51.244 & 305 \\
\hline França & 59.655 & 96 \\
\hline Itália & 55.057 & 92 \\
\hline Canadá & 38.348 & 116 \\
\hline Portugal & 11.017 & 104 \\
\hline
\end{tabular}

Fonte: International Centre for Prisions Studies, do King's College London

No Brasil, por exemplo, a política de encarceramento tem aumentado vertiginosamente ${ }^{4}$ nos últimos anos, tendo ultrapassado, no ano de 2010, a marca dos 496.000 presos. ${ }^{5}$ Segundo Lengruber (2007), o Brasil já havia atingido, no ano de 2006, o quarto

\footnotetext{
4. Segundo dados do Departamento Penitenciário Nacional, a população carcerária, que em 1988 era de 88.041 presos, o que representava taxa de encarceramento de 65,2 por cem mil habitantes, atingiu, em dezembro de 2010, espantosos 496.251 presos, elevando a taxa de encarceramento para 259,17 por cem mil habitantes. O aumento foi da ordem de 563\%, o que representa 408.210 presos a mais no sistema. In: Relatório Estatístico de 2010 Disponível em: http://portal.mj.gov.br/depen/data/Pages/D574E9CEITEMIDC37B2AE94C6840068B1624D28407509CPTBRIE.htm. Acesso em: 5 maio 2011.

5. "Se todos os mandados de prisão expedidos pela Justiça fossem cumpridos, estima-se que o número de detentos aumentaria em 550 mil" (Barbiere, 2008).
} 
lugar no ranking dos países com a maior população prisional, só perdendo para os Estados Unidos, China e Rússia. O sistema penitenciário brasileiro, por sua vez, ocupa, de acordo com dados do Departamento Penitenciário Nacional (Depen), ${ }^{6} 1.857$ estabelecimentos, com um total de 298.275 vagas (homens: 279.499 e mulheres: 18.776), e, portanto, déficit de quase 198.000 vagas.

Tal aumento, lógico, não é exclusividade nacional, dada a característica neoliberal de sua adoção. Wacquant (2001), ao analisar o inchaço das penitenciárias norte-americanas, comentou que "se fosse uma cidade, o sistema penitenciário americano seria a quarta metrópole do país". Esse encarceramento em massa reflete, de fato, uma estrutura de dominação contemporânea que mascara uma exclusão capitalista ainda mais perversa, o isolamento e a neutralização dos miseráveis em praticamente todo o globo.

Como bem assevera Christie (2002, p. 93), "são as decisões político-culturais que determinam a estatística carcerária e não o nível ou evolução da criminalidade". O maior encarceramento não tem, portanto, relação direta com o aumento das práticas criminosas, mas, sim, com o aumento dos miseráveis, totalmente excluídos do universo do trabalho.

Os cuidados com o "Estado ordeiro", outrora uma tarefa complexa e intricada que refletia as variadas ambições e a ampla e multifacetada soberania do Estado, tendem a reduzir-se consequentemente à tarefa de combate ao crime. Nessa tarefa, porém, um papel cada vez maior, com efeito o papel central, é atribuído à política de confinamento. A essencialidade do combate ao crime não explica por si só o boom penitenciário; afinal, há também outras maneiras de combater as reais ou supostas ameaças à segurança pessoal dos cidadãos. Além disso, colocar mais gente na prisão, e por mais tempo, até aqui não se mostrou a melhor maneira. É de supor, portanto, que outros fatores levam à escolha da prisão como prova mais convincente de que de fato "algo foi feito", de que as palavras correspondem à ação. Colocar a prisão como estratégia crucial na luta pela segurança dos cidadãos significa atacar a questão numa linguagem contemporânea, usar uma linguagem que é prontamente compreendida e invocar uma experiência comumente conhecida. (Bauman, 1999, p. 129)

Em suma, os processos de criminalização e encarceramento são determinados a partir de mecanismos econômicos e políticos, cumprindo, de forma eficaz, os interesses específicos da elite dominante: "a eliminação de indivíduos socialmente dispensáveis, perigosos, impróprios ao trabalho e à disciplina, figurando tais processos como os principais vetores para a realização do escoamento de mão de obra excedente e desqualificada", e para a consolidação do padrão moral de perseguição à pobreza (Rusche; Kirchheimer, 1999).

É justamente dessa forma, vale dizer, voltado preferencialmente para os miseráveis, que o aparato penal se articula na contemporaneidade. Segundo Wacquant (2001), essa transição entre o que ele denomina de "Estado Providência para o Estado-Penitência" destina-se "aos miseráveis, aos inúteis e aos insubordinados à ordem econômica e étnica que se segue ao abandono do compromisso fordista-keynesiano e à crise do gueto". O autor também observa que na Europa o encarceramento em massa funciona como "um aspirador social" que limpa "a escória resultante das transformações econômicas em andamento" e elimina do espaço público "o refugo da sociedade de mercado":

[...] pequenos delinquentes ocasionais, desempregados, indigentes, moradores de rua, estrangeiros clandestinos, toxicômanos, deficientes físicos e mentais deixados à deriva pelo enfraquecimento da rede de proteção sanitária e social, bem como jovens de origem modesta, condenados, para (sobre) viver, a se virarem como puderem por meios lícitos ou ilícitos, em razão da propagação de empregos precários. (Wacquant, 2004)

Também Bauman (1999) atenta para o fato de que a punição para as ações mais prováveis de serem cometidas por pessoas excluídas da ordem atual, pelos "pobres diabos tiranizados", tem a melhor chance de aparecer no código criminal.

Roubar os recursos de nações inteiras é chamado de "promoção do livre comércio"; roubar famílias e comunidades inteiras de seu meio de subsistência é chamado "enxugamento" ou simplesmente "racionalização". Nenhum desses feitos jamais foi incluído entre os atos criminosos passíveis de punição. [...] Só em casos raros e extremos os "crimes empresariais" são levados aos tribunais e aos olhos do público. Fraudadores do fisco e autores de desfalques têm uma oportunidade infinitamente maior de acordo fora dos tribunais do que os batedores de carteira ou assaltantes. (Bauman, 1999, p. 131-132)

"É provável que um só golpe sofisticado, arquitetado por criminosos de 'colarinho branco', renda prejuízo maior para a sociedade e para o Estado do que 
a soma de todos os roubos e furtos cometidos pelos miseráveis que se embrutecem nos cárceres" (Athayde et al., 2005, p. 188). Entretanto, os focos usuais dos órgãos de controle ainda são os flagrantes do estigma social, aqueles que põem em risco a ordem classista e o distanciamento seguro da elite.

Entre nós ficam cada vez mais evidentes as posturas autoritárias que, atreladas ao liberalismo contemporâneo, determinam um controle penal seletivo. Segundo estudos realizados pelo Ilanud (Jacobs, 2004), "o perfil para o presidiário brasileiro é de alguém majoritariamente pobre, do sexo masculino, de até 35 anos, com baixa escolaridade e baixa capacidade de inserção no mercado de trabalho". Isso demonstra claramente que também no Brasil se opera a criminalização da miséria, apontada por Wacquant na Europa.

Encarcerando cada vez mais e por mais tempo as classes populares, via de regra por pequenos delitos contra o patrimônio ou por condutas ligadas ao pequeno comércio de entorpecentes, desvia-se, de forma estratégica, a atenção dos inúmeros crimes contra a ordem econômica e financeira praticados pela elite política. Tal realidade denota claramente que a pobreza não está associada diretamente à criminalidade, mas sim "reproduz a vitimização ${ }^{7}$ e a criminalização dos pobres, o desrespeito aos seus direitos e a sua falta de acesso à justiça" (Caldeira, 2000, p. 134).

Ideologia mais do que consolidada, essa postura neoliberal em relação ao delito, além de radicalizar o controle penal, intensificando a atuação dos órgãos de controle, também restringe a liberdade e o exercício cívico das classes populares. Tal configuração política, denominada aqui de Estado punitivo, é centralizada na atuação punitiva, e evidencia-se na recorrência cada vez maior ao Direito Penal como solução em prima ratio de praticamente todos os conflitos sociais. Sua função, eminentemente simbólica, é atuar como mecanismo tranquilizador da opinião pública que, hegemonicamente, busca proteção ao invés de cidadania.

Essa onipresença penal demanda reformas institucionais apresentadas como tentativas de dar conta do suposto aumento da criminalidade violenta e do sentimento de insegurança que se verifica no âmago da sociedade civil. A pressão da opinião pública, amplificada pelos meios de comunicação de massa, aponta para o aumento do controle penal, tendo como paradigma preferencial o fortalecimento e a severidade no trato com o crime e o encarceramento em massa das classes populares.

Certamente, a essa altura não cabe mais a ingenuidade de supor que a legitimidade dessa postura penal não passa pela conjuntura econômica e política que vivenciamos.

Em tempos pós-modernos, o que caracteriza a atuação penal é a noção de emergência, entendida como um momento excepcional a exigir "uma resposta pronta e imediata, que deve durar enquanto o estado emergencial perdure" (Beck, 2004, p. 95). Essa noção de emergência, alimentada pelo medo social constante e estrategicamente introjetado, transforma os conflitos em ameaças e torna fácil desviar o cerne dos problemas, que não é de natureza conjuntural, mas social. Sob essa lógica, o Estado punitivo busca sua legitimidade exatamente lançando mão dos mecanismos de punição capazes de gerenciar a pobreza e disseminar o medo.

Aderindo fielmente a esse paradigma punitivo, o Estado brasileiro também descobriu que criminalizar é expediente fácil para garantir o sucesso das políticas neoliberais adotadas. Diante do medo hegemônico crescente, muitas vezes ampliado pelos meios de comunicação de massa, o sistema de justiça cumpre sua função orgânica de proteger as relações de produção vigentes.

Os valores expressos nessa lógica liberal delimitam o âmbito de atuação da nossa Justiça penal através de demandas sobre o sistema que devem absurdamente articular dois planos antagônicos: de um lado, a atividade se dá num contexto democrático; de outro, sua eficiência é julgada pelo grau de arbitrariedade, severidade e seletividade com que responde ao delito.

Nosso próprio ordenamento penal ${ }^{8}$ está impregnado de valores que refletem exatamente essa dominação autoritária, seletiva e excludente. Composto,

7. Uma das expressões mais dramáticas dessa realidade é representada pelos altos índices de homicídios que vitimizam predominantemente as populações mais carentes. De acordo com a Organização Mundial da Saúde, em seu último relatório sobre violência, a América Latina tem o pior registro de índices de homicídio no planeta. "O Brasil, um dos países mais violentos da região, acumulou mais de 800.000 mortes por homicídio doloso nas últimas duas décadas. Mais pessoas se tornam vítimas de homicídio a cada ano no Brasil do que na Guerra do Iraque. É importante dizer que uma ampla maioria dos mortos é economicamente desfavorecida, pouco instruída, jovem, masculina, negra e residente na periferia social brasileira" (Vieira, 2007, p. 43).

8. Apenas para ilustrar, nossa legislação penal prevê uma pena de oito a quinze anos de reclusão para aquele que, por menos de 24 horas, sequestrar pessoa com o fim de obter qualquer vantagem, como condição ou preço do resgate (art. 159 do Código penal). Absurdamente, nosso mesmo ordenamento estabelece uma pena bem inferior (reclusão de um a três anos) para aquele que, sem exigir qualquer vantagem, mantém alguém, indefinidamente, em cárcere privado (art. 148). Outro absurdo, que escancara tal dominação classista presente em nossa legislação, é a pena prevista para quem reduz alguém à condição análoga de escravo. Segundo o Código Penal (art. 149), reduzir alguém a condição análoga à de escravo, quer submetendo-o a trabalhos forçados ou a jornada exaustiva, quer sujeitando-o a condições degradantes de trabalho, quer restringindo, por qualquer meio, sua locomoção em razão de dívida contraída com o empregador ou preposto, sujeita o criminoso a uma pena de reclusão de dois a oito anos. 
em sua maioria, por penas que importam encarceramentos longos e degradantes, inclusive para menores, e que são associados em grande medida aos crimes tradicionais (praticados principalmente contra o patrimônio ou associados ao pequeno tráfico de entorpecentes), nosso corpo de leis está longe de representar um instrumento democrático de controle.

Nesse momento, portanto, apresenta-se como de fundamental importância ampliar as análises sobre as políticas penais adotadas pelos países de orientação neoliberal, que se alinham ao que a teoria sociológica contemporânea passou a denominar de Estado punitivo.

Se, como observou Garland (2008), a punição pós-moderna segregou ainda mais os setores marginais da população, intensificando uma retórica política de "tolerância zero", podemos associar essa postura reacionária ao desengajamento cada vez mais evidente no processo de individualização radicalizado na pós-modernidade.

\section{Referências}

ATHAYDE, Celso et al. Cabeça de porco. Rio de Janeiro: Objetiva, 2000.

BAUMAN, Zygmunt. Modernidade líquida. Rio de Janeiro: Jorge Zahar, 2001.

Globalização: as consequências humanas. Rio de Janeiro: Jorge Zahar, 1999.

BARBIERI, Cristiane. PPPs de prisões movimentam empresas. Folha de São Paulo. São Paulo, edição do dia 7/2/2008. Disponível em: http://www1.folha.uol.com. $\mathrm{br} / \mathrm{fsp} /$ dinheiro/fi0702200822.htm.

BATISTA, Nilo. Prezada senhora Viégas: o anteprojeto de reforma no sistema de penas. Discursos sediciosos. Crime, direito e sociedade. Rio de Janeiro, ano 5, $\mathrm{n}^{\circ} 9$ e 10, 2000. BECK, Francis Rafael. Perspectivas de controle ao crime organizado e críticas à flexibilização de garantias. São Paulo: IBCCRIM, 2004.

CALDEIRA, Teresa Pires do Rio. Cidade de Muros: crime, segregação e cidadania em São Paulo. São Paulo: Edusp e Editora 34, 2000.

CHRISTIE, Nils. Elementos de geografia penal. Discursos sediciosos. Crime, direito e sociedade. Rio de Janeiro, ano 7, no 11, 2002.

FOUCAULT, Michel. Microfísica do poder. Rio de Janeiro: Graal, 1995.

Vigiar e punir: nascimento da prisão. 12. ed. Tradução de Lígia Vassallo. Petrópolis: Vozes, 1987.

GARLAND, David. A cultura do controle: crime e ordem social na sociedade contemporânea. Rio de Janeiro: Revan, 2008.

As contradições da 'sociedade punitiva': o caso britânico. Revista de Sociologia e Política, no 13, 59-80, nov. 1999.

GIDDENS, A ;BECK, U; LASCH, S. Modernização reflexiva. Política, tradição e estética na ordem social moderna. São Paulo: Ed. Unesp, 1995.

GUINDANI, Miriam. Sistemas de política criminal: retórica garantista, intervenções simbólicas e controle social punitivo. Séries Cadernos Cedes/Iuperj. Rio de Janeiro, n' 2, 2005.

HARVEY, David. Condição pós-moderna. 15. ed. São Paulo: Loyola, 2010.
JACOBS, Claudia Silva. Para órgão da ONU, situação no sistema prisional é grave. BBC Brasil.COM. Brasília, edição do dia 5/5/2004. Disponível em: www.bbc.co.uk/ portuguese/reporterbbc/story/2004.

JAMESON, Fredric. Pós-modernidade e sociedade de consumo. Novos Estudos Cebrap. São Paulo, no 12, p. 1626, jun.1988.

LENGRUBER, Julita. Falta de política: Brasil tem a quarta maior população prisional do mundo. Consultor Jurídico. Edição do dia 3 de novembro de 2007. Disponível em: http://conjur.estadao.com.br/static/text/61024,1.

LÉVI-STRAUSS, Claude. Tristes trópicos. Trad. Rosa Freire d'Aguiar. São Paulo: Companhia das Letras, 1996. PAIXÃO, Antonio Luiz; BEATO, Claudio C. Crimes, cítimas e policiais. Revista de Sociologia da USP, v. 9, n 1 , maio, 1997.

RUSCHE, Georg; KIRCHHEIMER, Otto. Punição $e$ estrutura social. Rio de Janeiro: Freitas Bastos, 1999.

SALLA Fernando; GAUTO Maitê; ALVAREZ Marcos César. A contribuição de David Garland: a sociologia da punição. Revista Tempo Social, vol. 18, n¹, São Paulo, junho, 2006.

SANTOS, Boaventura de Souza. Pela mão de Alice: o social e o político na pós-modernidade. 8. ed. São Paulo: Cortez, 2001.

VIEIRA, Oscar Vilhena. A desigualdade e a subversão do Estado de Direito. Sur - Revista Internacional de Direitos Humanos. São Paulo: Prol, nº 6, ano 4, 2007.

WACQUANT, Loïc. Punir os pobres: a nova gestão da miséria nos EUA. Rio de Janeiro: Editora Freitas Bastos, 2007.

A aberração carcerária.Le Monde Diplomatique Brasil. Instituto Paulo Freire. Edição mensal de setembro de 2004. Disponível em: http://diplo.uol.com.br/2007-08, a1327 . 2001. As prisões da miséria. Rio de Janeiro: Jorge Zahar,

WAlMSLey, Roy. World Prison Population List (eighth edition). London: Centre for Prison Studies, King's College London, January, 2009.

ZAFARONI, Eugenio Raúl; PIERANGELI, José Henrique. Manual de Direito Penal brasileiro - parte geral. 4. ed. São Paulo: Editora Revista dos Tribunais, 2002. 


\title{
Punitive State and post-modernity
}

\begin{abstract}
This article presents the increasing investment in fighting crime by contemporary democracies, which helps to consolidate, also in Brazil, the image of the "punitive State". Inserted in the recent sociological reflections of Loïc Wacquant, David Garland, Nils Christie and Zygmunt Bauman, among others, this theme is still little discussed by the national academic community. The current capitalist arrangement is generalized, almost instantaneously, around the globe, tying the economic enterprises' success to the new criminal policy face. This article, therefore, aims to offer an alternative approach to reflections on social control, by addressing the so-called "punitive State" which adjusts to the economic, social and cultural transformations, already under way in the last thirty years, and that, according to some contemporary theorists, inaugurated the post-modernity.
\end{abstract}

Key words: punitive State, democracy, post-modernity.

\section{Estado punitivo y posmodernidad}

\section{Resumen}

El tema central de este trabajo es lo aumento de la inversión en la lucha contra la delincuencia en las democracias contemporáneas, lo que ayuda a consolidar, también en Brasil, la figura del "Estado punitivo". Presente en la reciente reflexións sociológica de Wacquant Loïc, David Garland, Nils Christie y Zygmunt Bauman, entre otros, este tema aún es poco discutido por la comunidad académica nacional. La propagación del sistema capitalista actual es casi instantánea en todo el mundo, que une el éxito de las empresas económicas a la nueva cara de la política criminal. El documento, por lo tanto, tiene como objetivo ofrecer un enfoque alternativo para pensar el control social analizando lo que ha sido llamado "Estado punitivo", politica adecuada a los cambios económicos, sociales y culturales ya en marcha en los últimos treinta años y que, según algunos teóricos contemporáneos, inauguran la posmodernidad.

Palabras-clave: Estado punitivo, democracia, posmodernidad.

Data de recebimento do artigo: 11/09/2011

Data de aprovação do artigo: 13/01/2012 